\title{
The Role of Group Psychotherapy in Psychiatric Residency Training
}

Shahbaz R. Khan M.D.

Katherine A. Cowan M.D.

Pedro Ruiz M.D.

Follow this and additional works at: https://jdc.jefferson.edu/jeffjpsychiatry

Part of the Psychiatry Commons

Let us know how access to this document benefits you

\section{Recommended Citation}

Khan, Shahbaz R. M.D.; Cowan, Katherine A. M.D.; and Ruiz, Pedro M.D. (1996) "The Role of Group Psychotherapy in Psychiatric Residency Training," Jefferson Journal of Psychiatry. Vol. 13 : Iss. 1 , Article 5.

DOI: https://doi.org/10.29046/JJP.013.1.004

Available at: https://jdc.jefferson.edu/jeffjpsychiatry/vol13/iss1/5

This Article is brought to you for free and open access by the Jefferson Digital Commons. The Jefferson Digital Commons is a service of Thomas Jefferson University's Center for Teaching and Learning (CTL). The Commons is a showcase for Jefferson books and journals, peer-reviewed scholarly publications, unique historical collections from the University archives, and teaching tools. The Jefferson Digital Commons allows researchers and interested readers anywhere in the world to learn about and keep up to date with Jefferson scholarship. This article has been accepted for inclusion in Jefferson Journal of Psychiatry by an authorized administrator of the Jefferson Digital Commons. For more information, please contact: JeffersonDigitalCommons@jefferson.edu. 


\title{
The Role of Group Psychotherapy in Psychiatric Residency Training
}

\author{
Shahbaz R. Khan, M.D., Katherine A. Cowan, M.D., \\ and Pedro Ruiz, M.D.*
}

\begin{abstract}
Group psychotherapy has become a well-recognized treatment modality in the mental health field. Educationally, however, group psychotherapy has not reached the priority level it deserves. We described our experiences in using group psychotherapy as a training tool at the University of Texas at Houston. In describing our program, we used case illustrations to better demonstrate the richness of our training experiences. Group psychotherapy should be more extensively used in the training of tomorrow's mental health professionals.
\end{abstract}

\section{HISTORY OF GROUP PSYCHOTHERAPY}

The field of group psychotherapy has grown considerably since Joseph Pratt formally introduced this treatment approach in 1905 (1). Nowadays, group psychotherapy has achieved international recognition as an empirically based effective intervention modality for persons suffering from emotional disorders in all age groups (2). Although Joseph Pratt first used this treatment modality with patients suffering from tuberculosis, he soon extended this group intervention to patients suffering from different types of chronic illnesses, including patients suffering from psychosomatic disorders (3). Following Pratt's original contributions, other therapists began using this treatment modality in their clinical practice and investigative efforts. Jacob Moreno, first in Europe and later in the United States used group concepts in the development of psychodrama (4). Additionally, psychoanalysts such as Paul Schilder and S.R. Slavson began to use group techniques based on psychoanalytic concepts (5). In 1942 the American Group Psychotherapy Association was founded and in 1951 the International Journal of Group Psychotherapy was initiated (6).

During World War II, group treatment had gained such momentum that William C. Menninger felt that group therapy was one of the major contributions of military psychiatry to the field at large (7). With the advent of the community mental health center movement in the 1960's, group psychotherapy greatly expanded in the United States (8). Among the most recent group therapy modalities with much

*All authors are affiliated with the Department of Psychiatry and Behavioral Sciences of the University of Texas/Houston Health Science Center where Dr. Khan is Senior resident, Dr. Cowan is Assistant Professor and Dr. Ruiz is Professor and Vice-Chair for Clinical Affairs. 
recognition and use, are Yalom's interpersonal techniques based on the here-andnow (9).

As the field of group therapy grew over the years, its utilization in the area of education also grew and, to a certain extent, in the area of research as well. In this article, we will attempt to describe our experience in developing a training-geared group therapy program for the purpose of offering an opportunity to learn group therapy techniques for psychiatric and psychology residents.

\section{TEACHING GROUP THERAPY}

Among the different settings in which psychiatrists learn group techniques, residency training has been considered the most important one (10). In 1980 over $91 \%$ of academically affiliated psychiatric residency training programs, in the United States, offered training in group therapy (11). In another related study (12), it was reported that the psychiatric residents' perception of the effectiveness of group therapy was directly related to their exposure to this modality of treatment during the course of their training. In this respect, in 1987 J.T. Slavendy, B. Robson and T. Babiak (11) conducted a survey among 134 psychiatric residents from the University of Toronto. Forty-seven percent (47\%) of the responders felt positively about the role of group therapy in the psychiatric field. By-and-large, these psychiatric residents were exposed to outpatient group therapy experiences during their training. In a similar study, E.M. Kahn, E.M. White and D.M. Hawkins (13), reported that 28\% of psychiatric residents exposed to group therapy training during their residency, including leading therapy groups, also led therapy groups after completion of their training program. These types of results indicate that exposure to group therapy training has a major impact on the future utilization of this treatment modality in clinical practice.

In another study about group therapy education, E.L. Perez, L.E. Krul and R. Kapoor (14) analyzed the perceptions about group therapy of all psychiatric residents in Canada. The results of this study demonstrated that most psychiatric residents in Canada do not think they received appropriate exposure to training in group therapy during their residency, and that high priority in their training programs was given to training and supervision in long term individual psychotherapy. These authors suggested that psychiatric residency training programs incorporate appropriate exposure and supervision in group psychotherapy practice within their didactic and clinical curriculum. Current pressures from managed care indicate that long term individual psychotherapy may not be available except to the wealthy and that psychiatrists with a broad variety of therapeutic skills will be most able to cope with changes in reimbursement patterns. Similarly, B.J. Saddock and H.I. Kaplan (15) have noted that early introduction to group psychotherapy experiences in psychiatric residency training was more likely to lead to the acceptance of this therapeutic modality on the part of the residents, as well as resolve any potential prejudices against this type of treatment intervention. This notion is particularly true 
in the training of most professional disciplines such as social work, psychology and psychiatry (10).

As S.R. Slavson (16) underlined it years ago, the presence of trainees in group psychotherapy permitted them to learn about how psychogenic factors affected mental illnesses, as well as permitted first hand observation of ego-defense mechanisms in action.

\section{THE TRAINING EXPERIENCE}

In the Spring of 1993, we decided to offer a clinical/training experience in group psychotherapy to the second and third year psychiatry and psychology residents rotating at the Mental Sciences Institute, the ambulatory component of the Department of Psychiatry and Behavioral Sciences of the University of Texas/Houston Health Science Center. Up to that time, there was not an official and systematic exposure to group therapy for the psychiatric residents of this program. Some psychology residents were exposed to group therapy during their one year internship program in the Department of Psychiatry and Behavioral Sciences, and an occasional psychiatric resident participated informally in groups led by staff clinicians.

In July 1, 1993, a required rotation of six groups was created, with a focus on a variety of conditions (chronic schizophrenia, psychotic disorders, women's mood disorders, sexual abuse survivors, mood disorders and dual diagnosis). Patients between the ages of 18 and 65 were considered eligible, twelve (12) patients were considered the maximum for each group, and all groups were led by the pairing of one psychiatric resident and one psychology resident. All groups were run for one hour a week, and forty-five minutes of supervision following the group meetings were provided by a faculty person assigned to this program.

The groups were intended to be open and eclectic. An appropriate room was assigned for this purpose, and medication monitoring, when needed, was handled as part of the training experience, at the group level. Confidentiality rules were upheld in all groups, and patients were asked to report to and discuss with the group any contacts among members outside of the group setting. Most psychiatric and psychology residents were assigned to a twelve month long training rotation in group therapy.

The group therapy training experience has so far been very well received by both trainees and faculty. There has been so much enthusiasm about this training experience that on two occasions the content of Grand Rounds presentations has focused on this group therapy exercise.

As a way of sharing the positive outcome of our group therapy training program, we would like to present, as case illustrations, some of the learning aspects of one of our therapy groups.

\section{CASE ILLUSTRATIONS}

The training group in question consisted of chronic schizophrenic patients. Most of the patients brought into the group had participated in medication groups in the 
past, but were never involved in groups focusing on the training of residents in the theory and practice of group psychotherapy. The Senior author of this article, a third year psychiatric resident during the academic year 1993-1994, was assigned to be the leader of this training group for that academic year. The group started in July of 1993 with eleven members. Their ages ranged from 29 to 53, with the average being 40.2 years old. There were two men and nine women when the group began. Of this number, five were white, five were African-American and one was HispanicAmerican. The group operated in an open-ended manner. The general topic of group discussion focused primarily on coping issues, behavioral problems, family relations and adjustments, and medication related issues. The supervision focused on technical aspects of group therapy, enrichment and personal factors. The book "The Theory and Practice of Group Psychotherapy" (9) was used as the reference book in supervision.

As the residents' training progressed, essential issues in group therapy were dealt with, such as offering support when needed, how to make appropriate interpretations, developing boundaries for the group, managing conflicts within the group, providing focus on the here-and-now, dealing with resistance among members, transferential issues, and other topics relevant to the training of residents. One of the most beneficial training experiences in the group was the learning about curative factors. A few case examples would best exemplify this learning process about curative factors.

\section{Instillation of Hope}

Ms. A., a 40 year old white female with a diagnosis of chronic schizophrenia, residual type, treated with haloperidol, stated that she was experiencing nightmares. In general, she tended to be withdrawn and mostly remained quiet during group therapy sessions. In describing her nightmares, she said that she saw herself repeatedly falling from a height and bouncing back on the floor after the fall. She felt very scared and anxious about these nightmares. After she finished describing the nightmares, several members of the group said they also suffered from disturbing nightmares. Another female member of the group said that the bouncing back in the Ms. A.'s dreams meant that she was very flexible, had a lot of strength, and that eventually she would conquer her fears about the nightmares. Ms. A. replied that she now felt very comfortable after receiving support and after seeing that she was not the only person suffering from bad dreams. Undoubtedly, Ms. A. received support and assurance from the group, thus developing hope about her problems.

In discussing this interaction in supervision the therapists were struck by the sincerity and authenticity of the instillation of hope. The patient had been able to accept it from her peers in a way that could not have come from an authoritarian traditional physician role. 
Ms. P., a 30 year old white female with a diagnosis of chronic schizophrenia, residual type, treated with haloperidol, stated, in one group session, that she still mourned her father who died a year ago. She further said that her father was a physician engaged in research. She had hoped that he would eventually discover a medication that could have cured her psychiatric condition. Unfortunately, he died before this desire of hers could become a reality. Following Ms. P.'s statement, the group leader interpreted to her that perhaps she was worried that no one else could help her now that her father was dead. Another member of the group said that she had heard about some promising research on new medications being developed for this disorder. Ms. P. acknowledged her fears in this respect, and thanked the members of the group for helping her to feel more hopeful about her illness. There were multiple levels of support given to this patient. The group functioned as a large, concerned family trying to nurture one of its members. The therapists learned about their parental roles in the group.

\section{Group Cohesiveness}

Ms. D., a 49 year old white female, with a diagnosis of chronic schizophrenia, residual type, treated with haloperidol and trazodone hydrochloride stated that her mood had been so depressed lately that she felt she would be better off dead. The group members knew that she lived alone and had infrequent contacts with her relatives. Following Ms. D.'s statements, almost all of the group members expressed their concerns for her, offering to stay with her if needed, and generally supported her in a strong cohesive manner. After this session, Ms. D. became more cheerful, more open about her depressed feelings and very active in group discussions. The therapist observed an immediate change in the patient's affect and behavior. She had become a more clearly valued part of the whole group. No longer an outsider, she had something to live for.

Ms. V., a 40 year old Hispanic-American female, with a diagnosis of chronic schizophrenia, disorganized type, treated with thioridazine hydrochloride, stated that she was considering discontinuing the group therapy because she lived far away, and the traffic was really bad in Houston. Immediately after Ms. V.'s statement several members of the group said that they loved her, and that she would be very much missed if she were to stop coming to the group. Also, two female group members told Ms. V. that she had helped them quite a bit, and that Ms. V. always was available to them when they felt bad. Ms. V. responded that she would continue to come to the group sessions, and never again mentioned dropping from the group. Again, the therapist was impressed by the power of the group to engage and nurture a member. 
Mr. R., a 40 year old white male, suffering from chronic schizophrenia, residual type treated with thiothixene hydrochloride, expressed that he was concerned about his recent change of medications. Subsequent to this statement, three members of the group spoke about their concerns in the past when their medications were changed. They said that eventually they adjusted well to the new medications, and that the new medications helped them a great deal. Mr. R. expressed comfort and reassurance about hearing from his fellow group members their similar experiences.

At a group therapy session, all members of the group spoke about their psychiatric symptoms. Towards the end of the session, several group members said that it was good to see that they were not alone in their suffering, and that everyone's symptoms in the group were somewhat similar.

\section{Self Understanding}

Ms. Z. was a hypertalkative member who often monopolized the group's time and attention with her own issues. Over the months, she was confronted by members of the group several times about her behavior, and she felt very hurt and defensive, feeling everyone disliked, criticized and rejected her. Actually, the group showed support and overall acceptance of her. Little change occurred in her pattern of domination of group time with her continuous talking. One day a member of the group told her that she could not stand sitting next to her because she gave her headaches. Ms. Z. acknowledged that she knew it was because she talked too much. Her response was different from previous times when she had become very defensive and hurt. She shared that when she was young she had a conflict with her father, who never believed in her and who tended to ignore her. She would talk persistently, raise her voice and repeat herself to him trying to gain acceptance. She needed to defend herself against a pervasive sense of ridicule and rejection. She now began to see that she had employed that pattern with everyone in her life. She verbalized recognition of her behavior with calmness, and expressed interest in working on it to bring about a permanent change.

\section{Interpersonal Learning}

Ms. F. complained to the group about a disabled friend who often spent the whole day playing dominoes with her. Although she enjoyed his company, she found the prolonged entertaining tiring and stressful. She said that because of his disability and loneliness she was unable to set any limits with him. Several members in the group shared that they also had similar experiences in the past. They pointed out that she was having difficulties dealing with her own emotions, especially her fear of rejection 
and her sense of guilt that she would hurt his feelings. The group acknowledged her experience and validated her feelings. They also provide support for her to set appropriate limits with him. Ms. F. was amazed at what everyone had to say, and verbalized she had indeed experienced those feelings. The intervention helped her recognize her conflicting emotions, and provided improved tools for interpersonal interactions.

The above case illustrations reflect the important effect that leading group psychotherapy can have on the training of psychiatric residents. When I was first assigned to lead this group I had little knowledge or skill in this treatment modality. Experience as a group leader was combined with readings from Yalom's book and direct supervision. As the weeks and months unfolded and my understanding of group psychotherapy grew, I began to appreciate how useful this treatment modality was for me as a resident. With this long term group, I became more aware of the complexities of the patients, I began to see more clearly their dynamic processes, and became more sensitive and empathic towards the chronically mentally ill.

The supervision time at the end of each group session focused primarily on the perceptions, feelings, and learning needs of the residents. After each session an hour was spent discussing with the supervisor the interactions among group members, as well as my own interaction with the group. Issues of transference and countertransference were recognized and processed. The supervision encouraged residents to research the available literature to address specific issues.

\section{CONCLUSION}

Group psychotherapy has become, during the last several decades, a well recognized treatment modality in the field of psychiatry. From an educational point of view, the importance of receiving training in group therapy has not reached, as yet, the level and priority that it deserves. Nowadays, with the current health care crisis and the constant emphasis on the utilization of cost-effective treatment interventions, group therapy looks very promising as a treatment modality. Based on these facts, we decided to make a strong emphasis on group therapy as part of our psychiatric residency training program and our psychology internship training program at the Department of Psychiatry and Behavioral Sciences of the University of Texas/Houston Health Science Center. After our first year of training experience, the outcome of our educational efforts in this regard has been quite satisfying and positive for trainees, faculty and, above all, for our patients. We hope that our educational experience will stimulate other psychiatric training programs throughout the nation to consider developing their own group training programs. Also, we hope to further stimulate research efforts in this very important treatment modality.

\section{REFERENCES}

1. Pratt JH: The "Home Sanatorium" Treatment of Consumption. Boston Medical Surgery Journal 1906; 154(8):210-216. 
2. Scheidlinger S: An Overview of Nine Decades of Group Psychotherapy. Hospital and Community Psychiatry 1994; 45(3):212-225.

3. Pratt JH: The Group Method in the Treatment of Psychosomatic Disorders. Sociometry 1945; 8:313-331.

4. Moreno JL: Who Shall Survive? Beacon, New York, Beacon House, 1953.

5. Schilder P: The Analysis of Ideologies as a Psychotherapeutic Method, Especially in Group Treatment. American Journal of Psychiatry 1936; 93(3):601-617.

6. Slavson SR: A Textbook in Analytic Group Psychotherapy. New York, New York, International University Press, Inc, 1964.

7. Menninger WC: Lessons from Military Psychiatry for Civilian Psychiatry. Mental Hygiene 1946; 30(4):571-589.

8. Peck HB: Some Relationships Between Group Process and Mental Health Phenomena in Theory and Practice. International Journal of Group Psychotherapy 1963; 13(3):269-289.

9. Yalom ID: The Theory and Practice of Group Psychotherapy. New York, Basic Books, 1985.

10. Pinney Jr. EL, Wells SH, Fisher B: Group Therapy Training in Psychiatry Residency Programs: A National Survey. American Journal of Psychiatry 1978; 135(12):1505-1508.

11. Salvendy JT, Robson B, Babiak T: Group Psychotherapy in Psychiatric Residency Training. Academic Psychiatry 1990; 14(1):27-33.

12. Casariego JI, Greben JF: Perceptions of Treatment Value, Therapeutic Orientation, and Actual Experience of Psychiatric Residents. Comprehensive Psychiatry 1978; 19(3):241248.

13. Kahn EM, White EM, Hawkins DM: Training in Group Psychotherapy: Residency Experience, Use in Practice and Self-Perception of Competence. Journal of Psychiatric Education 1986; 10(3):204-211.

14. Perez EL, Krul LE, Kapoor R: The Teaching of Psychotherapy in Canadian Psychiatric Residency Programs: Residents Perceptions. Canadian Journal of Psychiatry 1984; 29(12): 658-663.

15. Saddock BJ, Kaplan HI: Long-Term Intensive Group Psychotherapy with Psychiatric Residents as Part of Residency Training. American Journal Psychiatry 1970; 126(8):122_ 127.

16. Slavson SR: The Fields of Group Psychotherapy. New York, New York, International University Press, Inc., 1956. 